\title{
Power Generation at Room Temperature
}

Haruki Kohata ${ }^{1}$, Mitsugu Obinata ${ }^{2}$, Takumi Ikeda ${ }^{1}$, Hayato Sekiya ${ }^{1}$, Biao Mei $^{3}$, Ye Wang ${ }^{3}$,

Kazushi Mizukoshi ${ }^{3}$, Toshiro Isobe ${ }^{1}$, Akira Nakajima ${ }^{1}$, and Sachiko Matsushita ${ }^{1 *}$

${ }^{1}$ Department of Materials Science and Engineering, Tokyo Institute of Technology, 2-12-1 S7-8, Ookayama, Meguro-ku, Tokyo 152-8552, Japan, Tel.: +81-3-5734-2525, e-mail: matsushita.s.ab@m.titech.ac.jp

${ }^{2}$ Tohnic Co., Akabane 1361, Chigasaki, Kanagawa 253-0001, Japan

${ }^{3}$ R\&D Headquarters, Sanoh Co., Kounosu 758, Koga-city, Ibaraki, 306-0041, Japan

\begin{abstract}
The effective utilisation of thermal energy is crucial to a world aiming at sustainable development goals. The sensitised thermal cell (STC) is a new thermal energy conversion technology, which was reported in 2017, for generating electricity via the redox reactions of electrolyte ions with thermally excited carriers in semiconductors. STC is attracting attention as a technology that could affect oil prices globally. Here, we report the successful construction of STC, which discharges and recovers well at room temperature, by studying the interelectrode and ion diffusion distances. The fabricated STC is thinner than $0.5 \mathrm{~mm}$ and can be rendered flexible. Further, STCs, which possess a power generation capacity of $0.1 \mu \mathrm{A}, 100 \mathrm{mV}$ per $1 \mathrm{~mm}^{2}$ area, and shall be installed "in" internet-of-things (IoT) devices, drainage pipes, and walls in the future.
\end{abstract}




\section{Main text}

It is globally challenging to develop technologies that can control $\mathrm{CO}_{2}$ emissions without reducing the energy supply. The heat energy that is all around us is an attractive green energy source. ${ }^{1-3}$ Geothermal power generation ${ }^{4}$ and the Seebeck effect ${ }^{5}$ are the two main methods of generating electricity from heat. Regarding the former, electricity is generated via the rotation of a steam turbine, in which the heat used to generate the steam is supplied by a geothermal source. A major setback of this method is the availability of suitable land since the water demand is high. In the latter, electricity is generated via a temperature difference, which induces an electric potential. The device consists of at least two dissimilar conductors, and a complex design is required

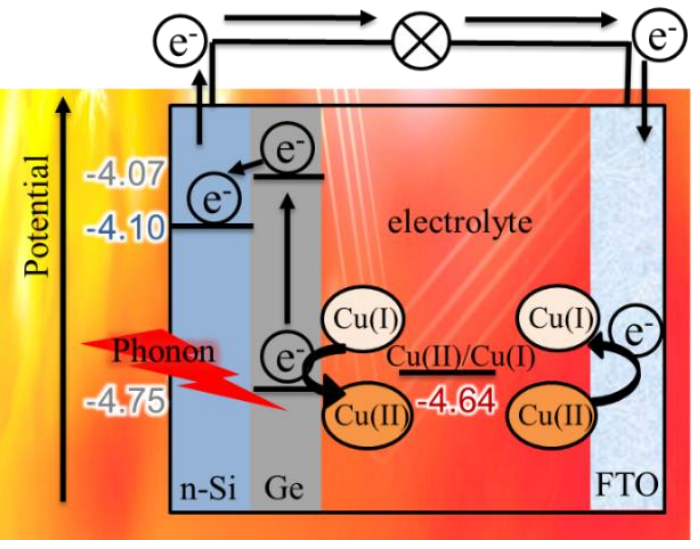

Fig. 1 Mechanism of STC. The thermally excited electric carriers reduce and oxidise the electrolyte ions to generate electric current at a constant temperature to ensure that it works under all possible conditions. To solve these problems, a new power generation method that could directly convert heat into electricity, therefore eliminating concerns with radioactive waste and enabling the use of renewable energy to generate electricity with a low environmental load using low-cost heat, is desirable.

We recently reported a sensitized thermal cell (STC) that is a new thermal energy conversion system ${ }^{6-11}$, which was inspired by the concept of a dye-sensitized thermal cell (DSSC). ${ }^{12-16}$ Utilising STCs, electric power can be generated "directly" from heat via the redox reactions of electrolyte ions with thermally excited carriers in semiconductors (Fig. 1). ${ }^{17,18}$ Since this battery can function at a constant temperature, we first expected that the generation of electricity would stop at some point when equilibrium is reached. attained. However, we surprisingly observed that the reaction could be restarted by the simple flip of an on/off switch in the external circuit. The discovery of the restart phenomenon means that STC is a technology that directly converts heat into electricity, which could affect the price of oil.

In this work, we examined the cause of this restart and acquired a guideline for designing batteries that can generate power at the desired temperature. As a result, we successfully reduced the power generation temperature from $80{ }^{\circ} \mathrm{C}^{19}$ to room temperature (RT, $30{ }^{\circ} \mathrm{C}$ ). The fabricated STCs were thinner than $0.5 \mathrm{~mm}$ and can be rendered flexible.

\section{What we firstly examined}

STC possesses a simple layered structure with a working electrode containing a semiconductor and a counter electrode sandwiching an electrolyte (Fig. 2a). To examine the "Restart" phenomenon, we focused on the distance 
(a)

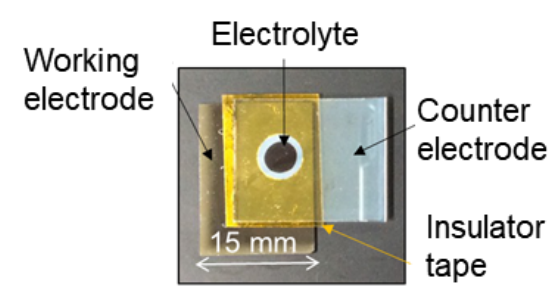

(c)

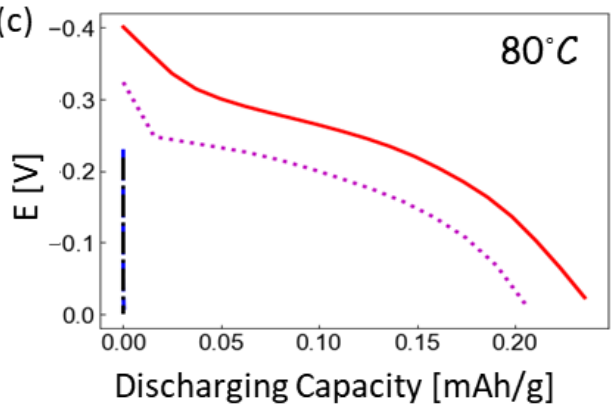

(b) $\underset{\xi}{\sum} 500$

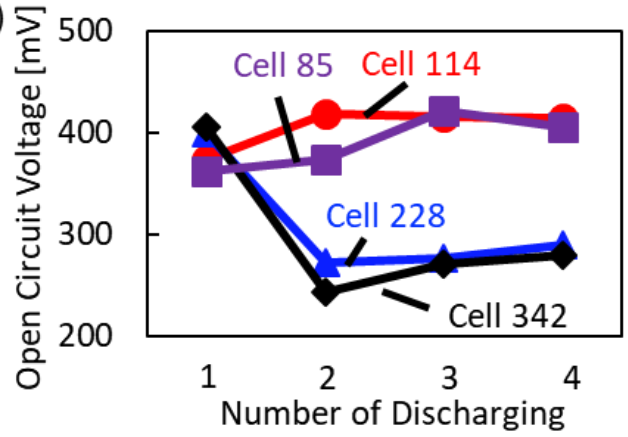

Fig. 2. Thinner cells can restart the power generation at $80^{\circ} \mathrm{C}$. (a) Appearance of the cell. (b) Changes in the open-circuit voltage (Voc) at $200 \mathrm{nA}$ discharging, and the chronoamperometries of the (c) 2nd and (d) 3rd discharging. Power generation was recovered in Cell-85 (electrode distance: $85 \mu \mathrm{m}$, purple dotted-line) and -114 (electrode distance: $114 \mu \mathrm{m}$, red solid line), but not in Cell-228 (electrode distance: $228 \mu \mathrm{m}$, blue dashed-line) and -342 (electrode distance: $342 \mu \mathrm{m}$, black dashed-dotted line).

between the working and counter electrodes. We fabricated 4 different cells with interelectrode distances of 85,114 , 228 , and $342 \mu \mathrm{m}$, respectively. The obtained cells were named according to their corresponding electrode distances (Cell$85,-114,-228$, and -342). The employed electrolyte volume was proportionally based on the interelectrode distance to eliminate the difference in the electrode/electrolyte contact area between each cell. A Ge-based semiconductor and a copper ion-based polyelectrolyte were selected for the STC materials..$^{9,10,19,20}$

The fabricated STCs demonstrated stable power generation at $80^{\circ} \mathrm{C}$ (Supporting Information (SI) 1). The open circuit voltage $\left(\mathrm{V}_{\mathrm{OC}}\right)$ of Cell-85, -114, -228, and -342 were approximately the same at 362, 373, 399 and $406 \mathrm{mV}$, respectively. The $\mathrm{V}_{\mathrm{OC}}$ value is caused by the difference between the redox potential of the electrolyte ions and the Fermi level of the working electrode. ${ }^{10}$ Comparing the discharge capacities of the 1 st $200 \mathrm{nA}$ discharge, that of Cell-342 was the smallest, thereby indicating that the sustainability of the power generation was influenced by ion convection inside the electrolyte.

After the initial discharge, all the batteries demonstrated voltage recoveries when they were switched off (SI 2). However, the time required to stabilise the voltage increased with increasing interelectrode distance. Cell- 85 recovered up to $0.35 \mathrm{~V}$ in few tens of seconds, while Cell-228 and -342 recovered up to $0.25 \mathrm{~V}$ in $4 \mathrm{~h}$, and this indicates that the interelectrode distance could affect the restart of STC. Notably, all the batteries were left in the thermostatic bath during discharge and restart processes. 
The $200 \mathrm{nA}$ discharge characteristics of each battery at $80^{\circ} \mathrm{C}$ were tested 4 times. In Cell-228 and -342 , the $V_{\text {OC }}$ after the $1^{\text {st }}$ discharge was $100 \mathrm{mV}$ smaller than the initial $V_{O C}$ (Fig. 2b). Contrarily, in Cell-85 and -114, the $V_{O C}$ attained the initial value after each discharge.

The $2^{\text {nd }}$ and $3^{\text {rd }}$ discharge curves are shown in Figs. $2 \mathrm{c}$ and $2 \mathrm{~d}$, respectively. The voltage rapidly dropped to zero in Cell-228 and -342 . Meanwhile, the $2^{\text {nd }}$ discharge capacities in Cell- 85 and -114 were 0.21 and $0.24 \mathrm{mAh} / \mathrm{g}$, while the $3^{\text {rd }}$ discharge capacities were 0.34 and $0.08 \mathrm{mAh} / \mathrm{g}$, respectively. It is noteworthy that the discharge capacity of Cell- 85 was higher than that of Cell-114.

These results strongly indicated that ion convection was crucial to the restart phenomenon (the cell can restart if sufficient ions are supplied to the electrode interface). Here we should mention that the $2^{\text {nd }}$ and $3^{\text {rd }}$ discharge capacities dropped more than the $1^{\text {st }}$ discharge. We think this is because of the polyelectrolyte ${ }^{21,22}$. During the first discharge, the electrolyte was not completely mixed at the molecular level, thus causing the diffusion of ions via local concentration distribution. Conversely, in the 2nd and 3rd discharge processes, power was generated after the complete mixing of the electrolyte in the first discharge, resulting in the shorten discharge time. These results suggested that ion diffusion in the electrolyte is reflected by the restoration of power generation by STC.

\section{Production of thinner cells}

Since the maximum characteristics were obtained with the thinnest cell (Cell-85) among the tested ones, we applied comb-shaped electrodes to assess what would happen if the interelectrode distance was narrower. Thus, we fabricated Ge and Pt comb-shaped electrodes on quartz, glass and a Kapton tape (Fig. 3a).

Two interelectrode distances ( 2 and $5 \mu \mathrm{m}$ ) were examined. The cells were referred to as Cell- 2 and -5 . These combshaped electrodes were filled with the electrolyte, and the battery characteristics were measured on a hot plate while controlling the temperature.

Surprisingly, Cell-2 did not generate power at $80{ }^{\circ} \mathrm{C}$ (Figs. $3 \mathrm{~b}$ and c). However, it generated power well as the temperature was lowered, and the best battery characteristics were obtained at $30^{\circ} \mathrm{C}$, which was near RT (SI 3a). We were so surprised that we also tried to generate power at room temperature (RT, $\sim 25^{\circ} \mathrm{C}$ under air conditioner), and confirmed that the power generation capacity ( $270 \mathrm{mV}$, Fig. 3d) was stable at least over $7000 \mathrm{~s}$. (Fig. 3e). This power generation and restore experiments will continue for several days, and the room temperature will change during that long experiments. In order to eliminate the effect of this temperature change, the following results were measured at $30^{\circ} \mathrm{C}$ fixed by a hot plate.

Cell-5 exhibited the same trend; it achieved good voltage recovery even after repeated discharge cycles (Fig. 3f). Particularly, the discharge time of Cell- 5 at $30^{\circ} \mathrm{C}$ was longer than that of Cell-2 (Fig. 3g). To understand the phenomenon, we measured the cyclic voltammetries (CVs) of Cell-2 at different scan rates at $30^{\circ} \mathrm{C}$ and $50^{\circ} \mathrm{C}$. We observed a capacitorlike behaviour at $50{ }^{\circ} \mathrm{C}$ (SI 3b and 3c). These results indicated that extremely short or long interelectrode distances are not desirable for restarting STC and that there is a 'just right' interelectrode distance.

\section{What happened?}


(a)
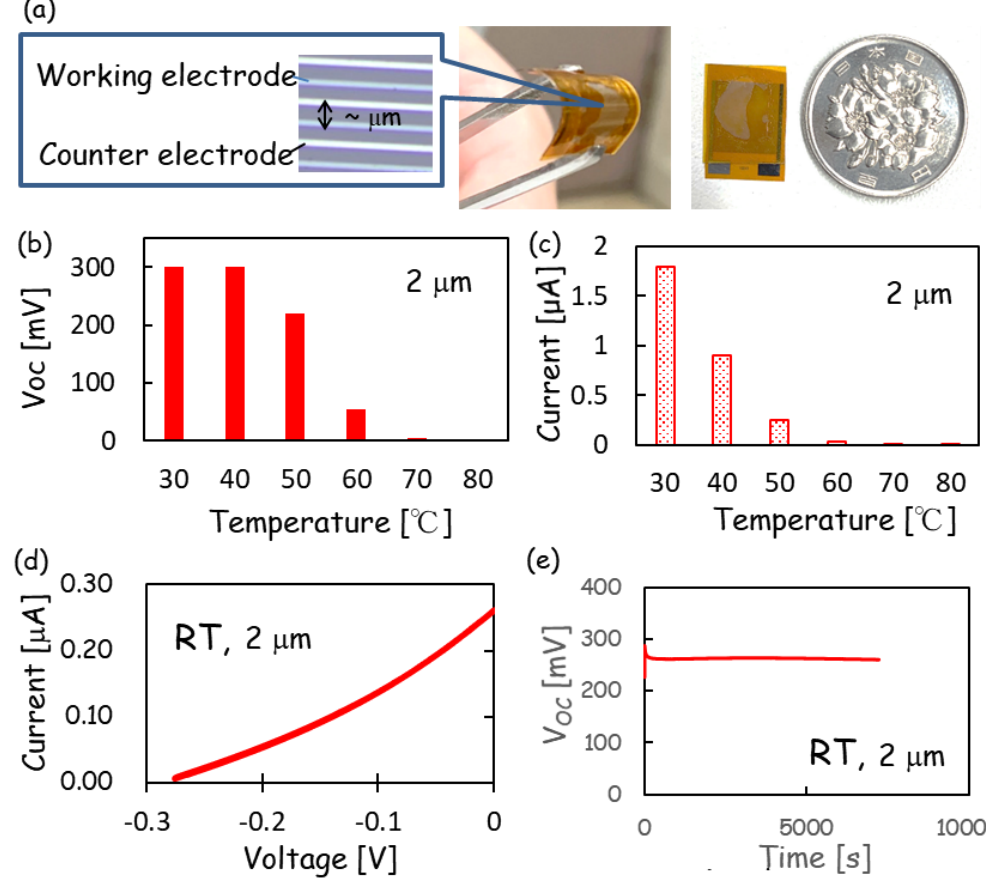

(e)
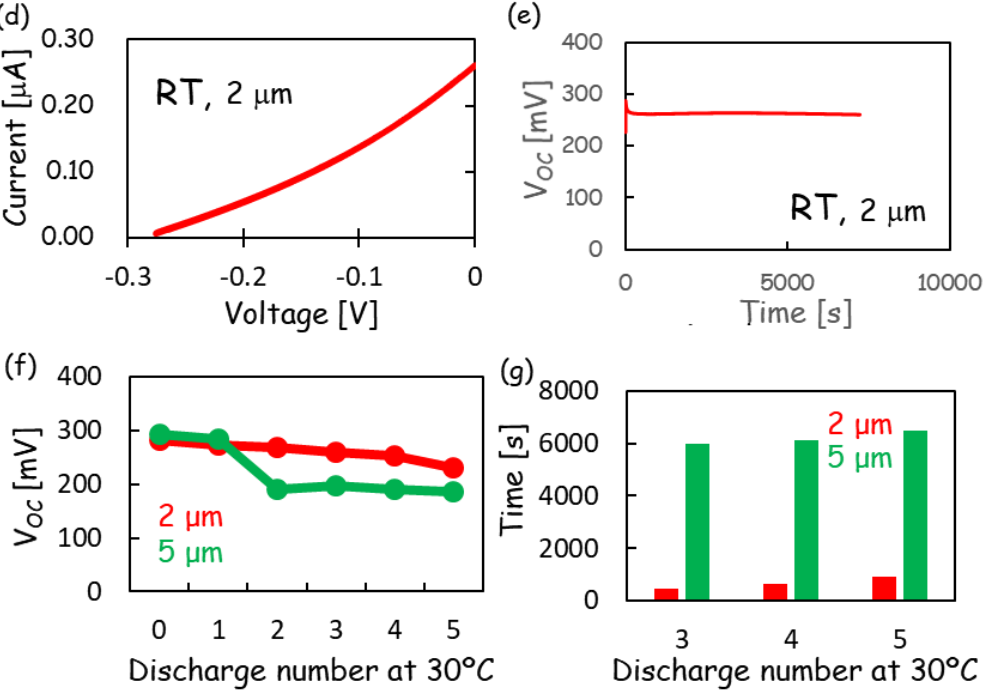

Fig. 3. (a) Thin, soft and light STC fabricated by depositing comb-shaped electrodes on a Kapton tape. These comb-shaped electrodes generated power at RT. (b) Temperature dependence of $V_{o c}$ and (c) short circuit current at an interelectrode distance of $2 \mu \mathrm{m}$. (d) CV (scan rate: $10 \mathrm{mV} / \mathrm{s}$ ) and (e) Voc measurement at RT at an interelectrode distance of $2 \mu \mathrm{m}$. ( $f$ ) Changes in $V_{o c}$ with the number of discharge and $(g)$ discharge time utilising the comb-shaped electrodes (interelectrode distance: 2 (red) and $5 \mu \mathrm{m}$ (green)) at $30^{\circ} \mathrm{C}$.

These results suggested that the ion diffusion length from the electrode surface affected the generation of power. Thus, we measured the ion diffusion length using the $\mathrm{AC}$ impedance measurement ${ }^{23}$ (SI 4). The results of the temperature change revealed that the ion diffusion length increased at higher temperatures (Fig. 4a). Conversely, the ion diffusion lengths of Cell-85, 114, 228 and 342 increased with decreasing interelectrode distances at $80{ }^{\circ} \mathrm{C}$ (Fig. 4b). During the power generation, a potential difference, $V$, was generated between the working and counter electrodes. The magnitude of the electric field, which was applied to the entire electrolyte, was equal to $V$ divided by the interelectrode distance. Resultantly, the electric field was larger with a shorter interelectrode distance, which made it easier for electrolyte ions to diffuse, thereby increasing the ion diffusion length.

From these measurements, it was confirmed that power generation occurred when the value $S$ (the interelectrode distance divided by the ion diffusion length) was between 1 and 10 . The same measurements were conducted for other STC systems, and power was generated at $1 \leq \mathrm{S}<10$ (SI 5). 
Based on these results, we considered the power generation and restore mechanism of STC (Figure 5). At $S<1$, the electrolyte ions behaved as a capacitor and did not move from the electrode interface. Hence, power was not generated (Fig. 5a). When $\mathrm{S}$ is too large, the electric field became small and the ions, which were generated at the Ge electrode (or counter electrode) interface did not diffuse to the counter electrode (or Ge electrode) interface and there was no restart (Fig. 5c). Put differently, STC generated and restored power well at $1<\mathrm{S}<10$, where ion diffusion constantly occurred.

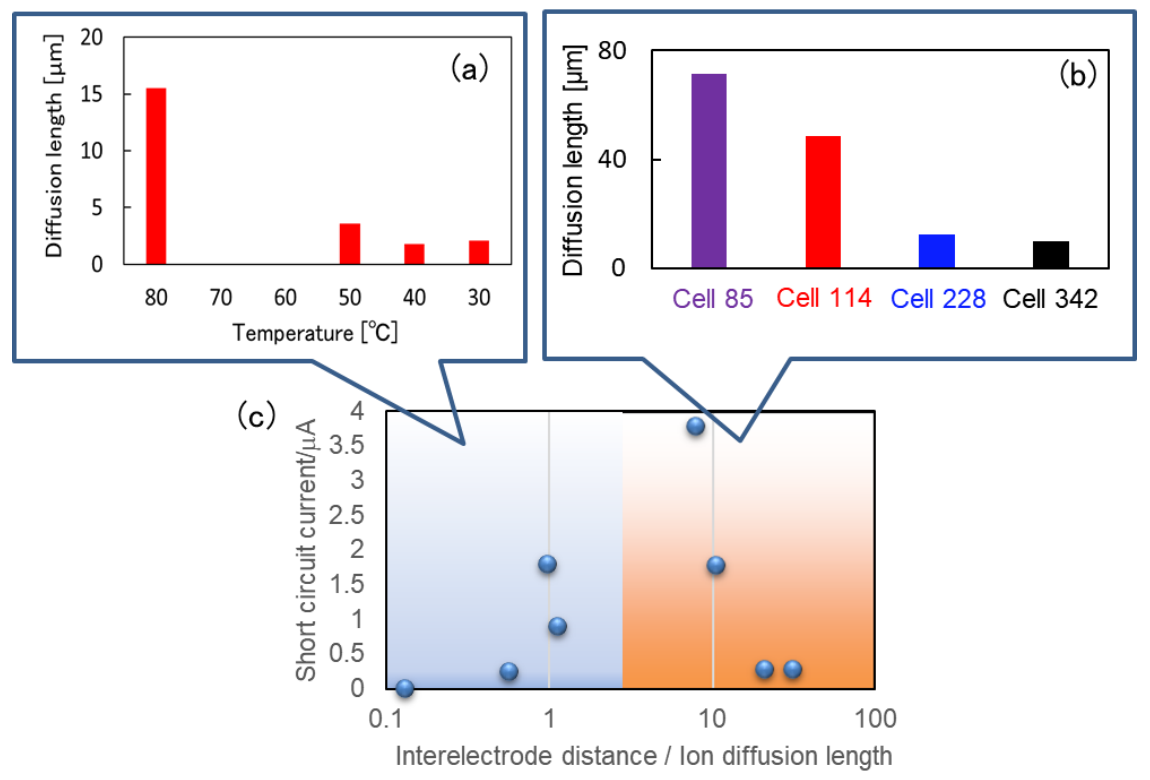

Fig. 4. Optimal values of the ion diffusion length and interelectrode distance. (a) Temperature dependence of the ion diffusion length in Cell-2 (a). (b) Ion diffusion lengths at $80^{\circ} \mathrm{C}$ in Cell-85, $-114,-228$ and 342. (c) Value obtained by dividing the interelectrode distance by the ion diffusion length. It correlates with the short-circuit current.

\section{Now we can design favourable STCS}

The ion diffusion length is a value that is determined by the electrolyte material and temperature. That is, if you measure the ionic diffusion length of the electrolyte at the temperature where you want to install the STC, and design the interelectrode distance to be several times longer than that, you can obtain an STC that would generate and restart power well. Since STC can be 'buried' in heat, it has been applied to operate liquid crystal displays at $80{ }^{\circ} \mathrm{C}^{9}$, Bluetooth communication devices on asphalt in the summer (SI 6). In principle, $\mathrm{V}_{\mathrm{OC}}$ of STC is independent of the temperature and is the difference between the Fermi level of the working electrode and the redox level of the electrolyte ions. ${ }^{10}$ Regarding $\mathrm{Ge} /\left(\mathrm{Cu}\right.$ ions in polyethylene glycol (PEG)) STC in this work, $\mathrm{V}_{\mathrm{OC}}$ was $\sim 0.35 \mathrm{~V}$. Assuming that the theoretical short-circuit current value was the number of reactive ions reaching the electrode interface per second, it would be estimated as $\sim 60$ and 
$150 \mu \mathrm{A} / \mathrm{cm}^{2}$ at $\mathrm{RT}$ and $80{ }^{\circ} \mathrm{C}$, respectively, for the $\mathrm{Ge} /(\mathrm{Cu}$ ion in PEG) STC combshaped electrode $(5 \mu \mathrm{m})$ based on the saturation concentration of the electrolyte, the ion mobility ${ }^{24}$ and electric field that were applied to the electrolyte (SI 7). This indicated that the output powers were 0.2 and $40 \mathrm{~mW} / \mathrm{cm}^{2}$ at $\mathrm{RT}$ and $60{ }^{\circ} \mathrm{C}$, respectively, which are comparable to that of solar cells (6 $\mathrm{mW} / \mathrm{cm}^{2}$ ) and are sufficient to employ STCs in IoT devices (sensor: $\mu \mathrm{W} \sim$, wireless power transmission: $\mathrm{mW} \sim)^{25}$. Evidently, these theoretical values were 'instantaneous' maxima, and the discharge and restore times would be the other major parameters to be considered for the practical application of STCs. (a)

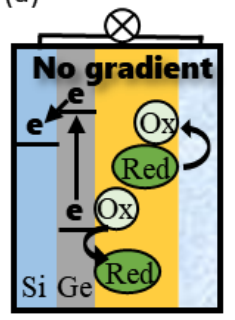

$S<1$

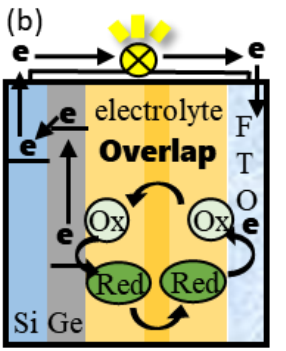

$1<5<10$

Good power generation!

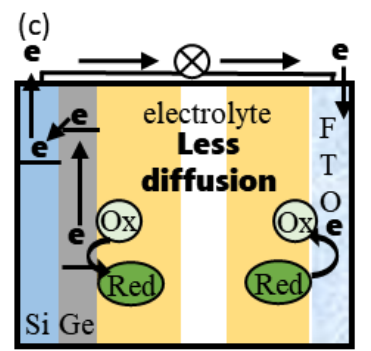

$10<5$

No restart
Fig. 5. Power generation of STC is related to S ( = interelectrode distance/ion diffusion length). (a) At $S<1, S T C$ behaved as a capacitor and did not generate power. (c) When $S$ was too large, the reacting ions did not diffuse from the counter electrode and did not restart. (b) When the ion diffusion lengths of both electrodes overlapped, STC exhibited good power generation and restart

We strongly expect our findings to offer huge energy markets for industries and academia as well as help achieve the control of $\mathrm{CO}_{2}$ emissions without reducing the energy supply, thereby contributing towards solving global environmental issues.

Acknowledgements. This work was partly supported by the JSPS WISE Program "InfoSyEnergy" (Doctoral Program for World-Leading Innovative \& Smart Education) from the Japan Society for the Promotion of Science (JSPS), COI-NEXT (JPMJPF2004), and Sumitomo Foundation; technically and financially supported by Sanoh Co., Japan, and Tohnic Co., Japan; and technically supported by Open Facility Center, Tokyo Tech., Japan.

\section{Author Contributions.}

H.K. planned the experiments and prepared and characterised the cells, and wrote the manuscript; M.O. planned the comb electrodes and fabricated; T.Ikeda and H.S. helped the impedance measurements and analysis; B.M. and Y.W. took the demonstration movie; K.M. measured TG-DTA; T.Isobe and A.N. prepared resources; S.M. managed and supervised the research project, and revised the manuscript.

\section{Competing Interests Statement.}

The authors declare no competing financial interests.

\section{Additional information}


Supplementary information is available for this paper at ...

\section{Material and Methods}

Wafer electrodes. The electrodes were composed of an $n$-Si/Ge substrate (Ge layer: $2 \mu \mathrm{m}$ ) that was manufactured by Tohnic Corporation, Japan. A Cr layer $(20 \mathrm{~nm})$ was sandwiched in the $n$-Si wafer $(0.02 \Omega \mathrm{cm}, 15 \times 20 \times 0.5 \mathrm{~mm})$ to improve the adhesion of the $\mathrm{n}-\mathrm{Si} / \mathrm{Ge}$ interface. The resistivities of the $n$-Si and Ge sides, which were measured by the 4probe method (Loresta GP MCP-T600, Mitsubishi Chemical Corporation) at RT, were 3.18 and 3.27 $\Omega /$ sq, respectively. The counter electrode was composed of fluorine-doped tin oxide (FTO, $10 \Omega, 15 \times 25 \mathrm{~mm}$ ).

Comb electrodes. A comb electrode with 2 materials, Pt and Ge, was used (Tohnik Co., Ltd.). Ge (1 $\mu$ m thickness) and Pt (30 $\mu \mathrm{m}$ thickness) were deposited on a synthetic quartz substrate with a thickness of $0.525 \mathrm{~mm}$ and an area of $1 \mathrm{~cm}^{2}$. The comb electrode widths were 2 and $5 \mu \mathrm{m}$ for the electrode distances of 2 and $5 \mu \mathrm{m}$, respectively, and the area of the comb-shaped electrode part was $0.04 \mathrm{~cm}^{2}$. For the demonstration, we also fabricated the comb electrodes on a kapton tape.

Electrolytes. Since Ge is a water-labile material, the electrolyte was prepared in a flow-type glove box, coupled with a circulation/purification machine, filled with $\mathrm{Ar}$ (the oxygen concentration was $0.2-0.5 \mathrm{ppm}$ ). Before the reagents were used in the glove box, they were vacuumed at $80^{\circ} \mathrm{C}$ for $15 \mathrm{~h}$ in a side box. Furthermore, the molecular sieves (Fujifilm Wako Pure Chemical Industries, Ltd.) were heated for 3 and $4 \mathrm{~h}$ at 180 and $350{ }^{\circ} \mathrm{C}$ in an electric furnace, respectively, after which they were cooled to $\sim 50{ }^{\circ} \mathrm{C}$ in a vacuum desiccator before they were added to PEG600 to approximately one-third of its original volume for dehydration.

After introducing the reagent into the glove box, the concentrations of $\mathrm{CuCl}, \mathrm{CuCl}_{2}$ and $\mathrm{LiCl}$ were weighed 0.5, 0.5 and $0.6 \mathrm{mmol} / \mathrm{g}$ (PEG), respectively. The components were mixed for $10 \mathrm{~min}$ utilising a mortar and a pestle.

The thermal analysis of the electrolyte was performed by thermogravimetry-differential thermal analysis (TGDTA). In this analysis, $7.28 \mathrm{~g}$ of the electrolyte was heated from RT to $180{ }^{\circ} \mathrm{C}$ in an $\mathrm{N}_{2}$ flow and at a heating rate of $1{ }^{\circ} \mathrm{C} / \mathrm{min}$. The thermal behaviour of the electrolyte was compared with that of PEG (the reference material), and three samples comprising PEG and $\mathrm{CuCl}, \mathrm{PEG}$ and $\mathrm{LiCl}$ and $\mathrm{PEG}$ and $\mathrm{CuCl}_{2}$ were selected to investigate the influence of each reagent.

Cell assembly. The FTO substrate was ultrasonically cleaned with ethanol for $7 \mathrm{~min}$, and a double-sided insulating tape with a hole (6 mm dia.) was attached to it. 4 electrode distances $(85,114,228$ and $342 \mu \mathrm{m})$ were achieved using two types of insulating tapes (a double-coated Kapton Polyimide Film P-223, Nitto, Japan, thickness: $114 \mu \mathrm{m}$ and an adhesive tape API214A-25X10, Chukoh, Japan; thickness: $85 \mu \mathrm{m})$. The $n$-Si/Ge substrate was immersed in a solution of $5 \% \mathrm{HF}$ for $5 \mathrm{~min}$, after which it was rinsed three times with ion-exchanged water for 1 min to remove the oxides on the surface. The FTO and Ge substrates were inserted in the glove box in which all the cell-fabrication processes 
were performed. Thereafter, the copper-ion-based electrolyte was proportionally dropped into the hole of the insulating tape according to the thicknesses of the tapes to eliminate the difference in the contact area of the electrode/electrolyte between each cell. Therefore, 0.78, 1, 2 and $3 \mu \mathrm{L}$ of the electrolyte were dropped when the thicknesses of the tape were 85, 114, 228 and $342 \mu \mathrm{m}$, respectively. Afterwards, the $n$-Si/Ge substrate was placed to cover the hole. The obtained cells were named according to their corresponding electrode distances (Cell-85, -114, -228 and $342)$.

Performance of the sheet-type cells. The following measurements were performed on each cell at an environmental temperature of $80^{\circ} \mathrm{C}$ : CV was measured with a VSP-300 instrument (Bio-Logic) in a system composed of two electrodes. The scan rate was $10 \mathrm{mV} / \mathrm{s}$, and the sweep direction was oppositive than that of $\mathrm{V}_{\mathrm{OC}}$.

A procedure, which consisted of a combination of the $\mathrm{V}_{\mathrm{OC}}$ and chronopotentiometry (CP) measurements, was applied to achieve the long-term operation measurements. In the CP method, the current was set to $200 \mathrm{nA}$, and the procedure was terminated when the voltage dropped to zero. Afterwards, $\mathrm{V}_{\mathrm{OC}}$ was recorded every 0.5 seconds until a stable value was achieved in the final $1 \mathrm{~h}$. This procedure was repeated 3 times under the same heat source and subjection to the atmosphere.

Electrochemical impedance spectroscopy (EIS), in which the potentiostat and galvanostat EIS (PEIS and GEIS, respectively) were adopted to measure the impedance of the system, was also performed. In PEIS, the amplitude of AC was set to $10 \mathrm{mV}$, while in GEIS, a constant current of $200 \mathrm{nA}$ (the same value in the CP measurement) and a sinus amplitude of $300 \mathrm{nA}$ were applied. Furthermore, in both methods, the measurement frequency ranged from $7 \mathrm{MHz}$ to 50 $\mathrm{mHz}$. Z-view was employed for the fitting.

Performance of comb electrode cells. The electrolyte $(1.5 \mu \mathrm{L})$ was dropped onto the comb electrode, which was covered afterwards with a glass cover $(18 \times 18 \times 0.12-17 \mathrm{~mm}$, Matsunami). The CV measurement was conducted with two electrodes at a scanning speed of $10 \mathrm{mV} / \mathrm{s}$. In the $\mathrm{CP}$ measurement, the current was set to $100 \mathrm{nA}$, and the procedure was terminated when the obtained voltage dropped to zero. Regarding the $\mathrm{V}_{\mathrm{OC}}$ measurement, $\mathrm{V}_{\mathrm{OC}}$ was recorded every $10 \mathrm{~s}$, and the measurement time was set to $2 \mathrm{~h}$. The long-term operation measurement was performed by combining the $\mathrm{CP}$ and $\mathrm{V}_{\mathrm{OC}}$ measurements and repeating the $\mathrm{CP} \rightarrow \mathrm{V}_{\mathrm{OC}}$ measurement five times at $\mathrm{RT}$ to evaluate the discharge and subsequent restore performances of the battery.

Bluetooth communication devices on asphalt. Four STC coin cells (assembled by Sanoh, Co. using n-Si/Ge wafer) in series were connected to a battery-less wireless sensor (CLEAN-Boost technology, ABLIC Inc., Japan) and placed on the asphalt. A tester (CD771, SANWA) was also connected to the sensor to determine the voltage. The temperature on the asphalt was measured with a Thermometer (FT3700, HIOKI). The Bluetooth signal generated was received by the smartphone using nRF Connect for Mobile.

\section{References}


Wang, Z. et al. Dynamic tuning of optical absorbers for accelerated solar-thermal energy storage. (Nature Communications., 8, Article number: 1478, 2017).

Cottrill, A. L. et al. Ultra-high thermal effusivity materials for resonant ambient thermal energy harvesting. (Nature Communications., 9, Article number: 664, 2018).

Shi, X. et al. Enhanced water splitting under modal strong coupling conditions. (Nat. Nanotechnol., 13, 953-958, 2018).

Pambudi, N. A. Geothermal power generation in Indonesia, a country within the ring of fire: Current status, future development and policy. (Renewable Sustainable Energy Rev., 81, 2893-2901, 2018).

$5 \quad$ Elsheikh, M. H. et al., (Renewable Sustainable Energy Rev., 30, 337-355, 2014).

6 Matsushita, S., Tsuruoka, A., Kobayashi, E., Isobe, T. \& Nakajima, A. Redox reactions by thermally excited charge carriers: towards sensitized thermal cells. Mater. Horiz. 4, 649-656 (2017).

7 Matsushita, S., Sugawara, S., Isobe, T. \& Nakajima, A. Temperature Dependence of a PerovskiteSensitized Solar Cell: A Sensitized “Thermal” Cell. ACS Appl. Energy Mater. 2, 13-18 (2019).

8 Inagawa, Y., Isobe, T., Nakajima, A. \& Matsushita, S. Ag ${ }_{2} \mathrm{~S}-$ Sensitized Thermal Cell. J. Phys. Chem. C123, 12135-12141 (2019).

9 Matsushita, S. et al. A sensitized thermal cell recovered using heat. J. Mater. Chem. A 7, 1824918256 (2019).

10 Matsushita, S. et al. Fermi Level Dependence of a Working Electrode on the Open Circuit Voltage in a Sensitized Thermal Cell. Chem. Lett. 49, 1013-1016 (2020).

11 Matsushita, S. Development of a sensitized "thermal" cell. Vol. 11387 SI (SPIE, 2020).

12 O'Regan, B. \& Gratzel, M. A low-cost, high-efficiency solar cell based on dye-sensitized colloidal $\mathrm{TiO}_{2}$ films. (Nature., 353, 737-740, 1991).

Nazeeruddin, M. K., Baranoff, E. \& Gratzel, M. Dye-sensitized solar cells: A brief overview. (Solar Energy., 85, 6, 1172-1178, 2011).

14 Yun, S. et al. New-generation integrated devices based on dye-sensitized and perovskite solar cells. Energy Environ. Sci. 11, 476-526 (2018).

15 Pinpithak, P., Kulkarni, A., Chen, H.-W., Ikegami, M. \& Miyasaka, T. Solid-State Thin-Film DyeSensitized Solar Cell Co-Sensitized with Methylammonium Lead Bromide Perovskite. Bulletin of the Chemical Society of Japan 91, 754-760 (2018).

16 Fukuda, T. et al. Limiting factor of performance for solution-phase ligand-exchanged $\mathrm{PbS}$ quantum dot solar cell. Solar Energy Materials and Solar Cells 195, 220-227 (2019).

17 Matsushita, S., Sugawara, S., Isobe, T. \& Nakajima, A. Temperature Dependence of a PerovskiteSensitized Solar Cell: A Sensitized “Thermal” Cell. (ACS Appl. Energy Mater., 2, 13-18, 2019). 
18 Matsushita, S., Tsuruoka, A., Kobayashi, E., Isobe, T. \& Nakajima, A. Redox reactions by thermally excited charge carriers: towards sensitized thermal cells. (Material Horizons., 4, 649-656, 2017).

19 Matsushita, S. et al. A sensitized thermal cell recovered using heat. (J. Mater. Chem. A, 7, 1824918256, 2019).

20 Matsushita, S. Development of a sensitized "thermal" cell. SPIE Defense + Commercial Sensing (Invited paper) 11387 (2020).

21 Muthukumar, M. 50th Anniversary Perspective: A Perspective on Polyelectrolyte Solutions. Macromolecules 50, 9528-9560 (2017).

22 Tirrell, M. Polyelectrolyte Complexes: Fluid or Solid? ACS Central Science 4, 532-533 (2018).

23 Nguyen, T. Q. \& Breitkopf, C. Determination of Diffusion Coefficients Using Impedance Spectroscopy Data. J. Electrochem. Soc. 165, E826-E831 (2018).

24 Fragiadakis, D., Dou, S., Colby, R. H. \& Runt, J. Molecular Mobility, Ion Mobility, and Mobile Ion Concentration in Poly(ethylene oxide)-Based Polyurethane Ionomers. Macromolecules 41, 57235728 (2008).

25 Meile, L., Ulrich, A. \& Magno, M. in 2019 IEEE 8th International Workshop on Advances in Sensors and Interfaces (IWASI). 312-317. 